\title{
Custom-made Ocular Prosthesis for Rehabilitation of Missing Parts of the Face: A Case Report
}

\author{
Imam Safari Azhar, DDS, MSc, ${ }^{1}$ Rizko Wira Artha Megantara, DDS² and Agus Dahlan, DDS, MSc ${ }^{1}$ \\ ${ }^{1}$ Department of Prosthodontics, Faculty of Dental Medicine, University of Airlangga, Surabaya, Indonesia \\ ${ }^{2}$ Resident of Prosthodontics, Faculty of Dental Medicine, University of Airlangga, Surabaya, Indonesia
}

\begin{abstract}
Background. Eyes are an important component of the face and vital organs of vision. Eye loss can be caused by congenital defects, trauma, or tumor. Loss of an eye produces physical abnormalities that pose a psychological burden on the patient, as well as visual function damage. An ocular prosthesis is an artificial maxillofacial prosthesis to replace the lost eye.
\end{abstract}

Case summary. A 54-year-old man consults at the Prosthodontics Specialist Universitas Airlangga Dental Hospital for an eye prosthesis. The patient did not have the right eyeball since birth. Soft tissue around the eye is normal, including the palpebral muscles.

Case management. An impression was made using a custom tray and alginate in the defect area, followed by filling the impression with gypsum type 3 to get a working model, from which a wax model is made and adjusted to the patient. After that, sclera and ocular acrylic prostheses are made on the basis of an adjusted wax model. The prosthesis is then polished and colored according to the contralateral eye. Then the prosthesis is delivered to the patient.

Conclusion. The hollow custom-made eye prosthesis can be considered in the treatment of anophthalmia. It is able to improve the patient's psychological and emotional status.

Key Words: eye, ocular prostheses, ocular defect, social determinants of health

\section{INTRODUCTION}

Paper presented in the Temu IImiah Nasional dan Internasional ke-8 (TIMNASS 8) - Faculty of Dental Medicine, Universitas Airlangga, Surabaya, Indonesia.

Corresponding author: Imam Safari Azhar, DDS, MSc

Department of Prosthodontics

Faculty of Dental Medicine

University of Airlangga

Surabaya, Indonesia

Email: imam-safari-azhar@fkg.unair.ac.id
Eyes are an important component of the face and viral organs of vision. Eye loss can be caused by congenital defects, trauma or tumor. Loss of eye produces physical abnormalities, visual function damage, as well as psychological burden on the patient. In eye loss, it is very necessary to do early rehabilitation to alleviate psychological suffering. An ocular prosthesis is an artificial maxillofacial prosthesis that replaces the lost eye. Prosthesis do not replace the eyelid skin, mucosa or muscles that are close together. ${ }^{1}$ Eye prosthesis made of glass and porcelain were created by Ambroise Pare, maxillofacial prosthodontist. During and after World War II, artificial glass eye prosthesis was made from acrylic material. The advantages of acrylic resin eye prosthesis include: easy to install and adjust, durable and not easily broken, aesthetically pleasing, and easy to make. ${ }^{2}$

Ocular eye prosthesis can be classified into two types; stock eye and custom-made eye prosthesis. The advantages of custom-made eye prostheses include: having good contact with eye soft tissue, less fluid accumulation between tissue and prosthesis with reduced possibility of tissue irritation and bacterial growth. Custom-made eye prosthesis 

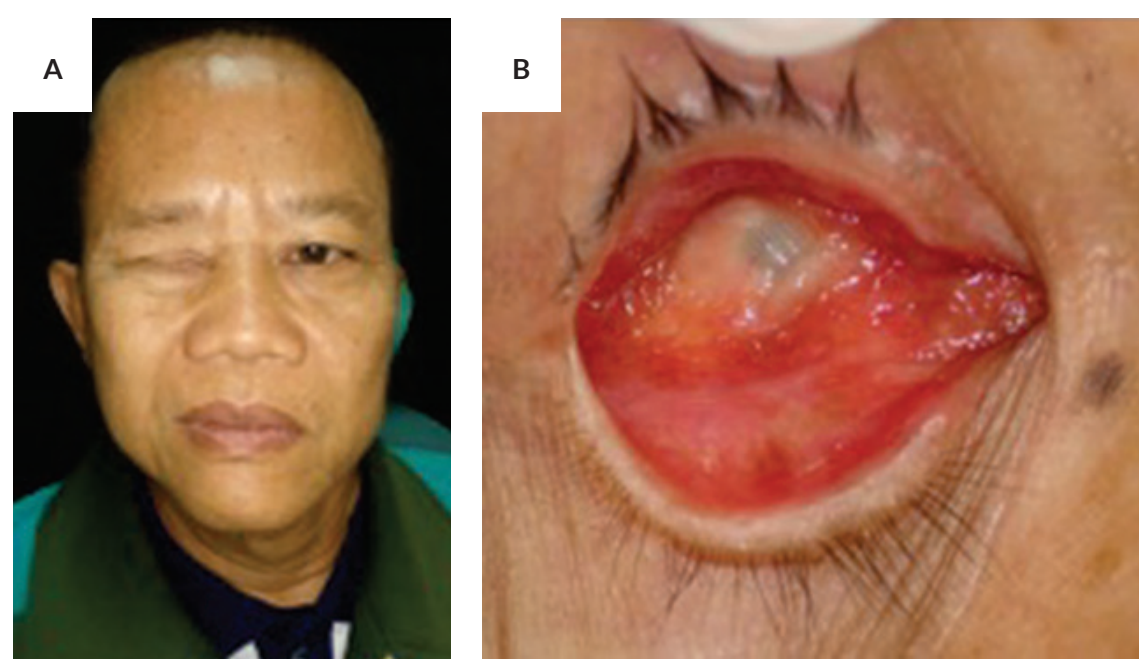

Figure 1. Clinical case of the patient. (A) Front view of the patient's entire face; (B) Right eye defect.

distributes pressure more evenly and reduces the incidence of conjunctival abrasion compared to stock prosthesis. ${ }^{3,4}$

The custom-made ocular prosthesis has the advantage of providing maximum comfort and adaptation that is close to the network bed. This article describes the rehabilitation of eye defects by ocular prosthesis in a man. Recovery after losing the eye needs adjustments to eyesight and improved appearance. With the use of artificial eyes that are prepared with care to match the eyes naturally remaining, maxillofacial prosthesis improves quality of life of patients, builds confidence and restores a normal social life. ${ }^{5}$

This article aims to discuss prosthetic rehabilitation in anophthalmic patients and the techniques used in the manufacture of ocular prostheses. Management of eye defects with proper diagnosis and treatment planning, as well as rehabilitation with appropriate maxillofacial prostheses are expected to improve the cosmetic and psychological level of the patient.

\section{CASE SUMMARY}

A 54-year-old man consulted at the Prosthodontics Specialist Universitas Airlangga Dental Hospital for an eye prosthesis. The patient did not have his right eyeball since birth. Soft tissue around the eye is normal, including the palpebral muscles. A custom-made eye prosthesis is planned for the patient. The patient agreed and signed an informed consent regarding the treatment plan to be carried out at Universitas Airlangga Dental Hospital (Figure 1).

The patient's eye socket was cleaned with saline and cotton, after which work models were printed with elastomer, using a custom tray made especially of the self-cured acrylic material with an added iron rod as a tray handle (Figure 2). The custom tray was perforated to retain the impression materials.

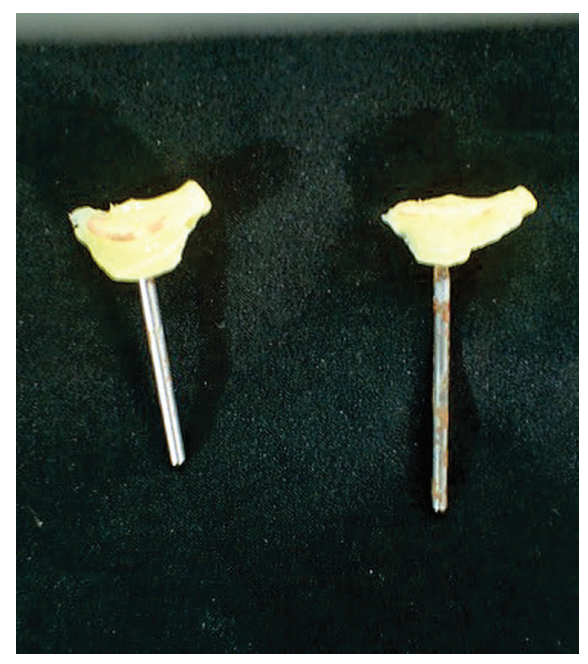

Figure 2. Custom tray.

The patient sat in a supine position on the dental unit and was instructed to look straight forward. The custom tray was placed in the socket after the alginate was put in the eye socket so that the impression material fills up the entire eye. The patient was then asked to close his eyes so that alginate excess can come out and then perform various eye movements to record functional forms. The custom tray was removed after setting material.

The mold was then cast in a gypsum type III (Dental Stone) to get a working model. A wax model made with modeling wax (Cavex) was placed into the socket of the working model. It was then fitted into the patient based on the position and measurements of the iris. The wax model was used to verify size and support from the surrounding tissue to simulate eye movements and coverage of the eyelids. The color of the sclera of the contralateral eye was used as a guide, with the use of tooth-colored acrylic material (Figures 3 and 4).

After the wax model was corrected, the next step was acrylic packing. The acrylic material used was selfcuring acrylic. The acrylic packing was smoothened, with a
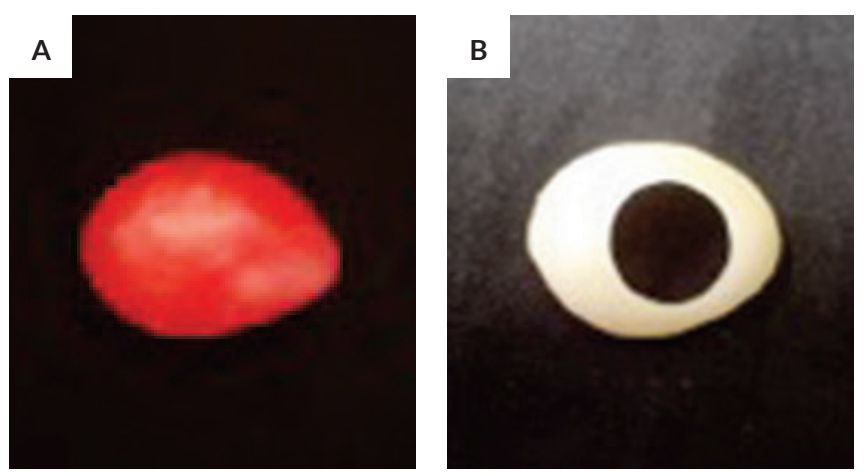

Figure 3. (A) Ocular wax model; (B) Acrylic sclera. 

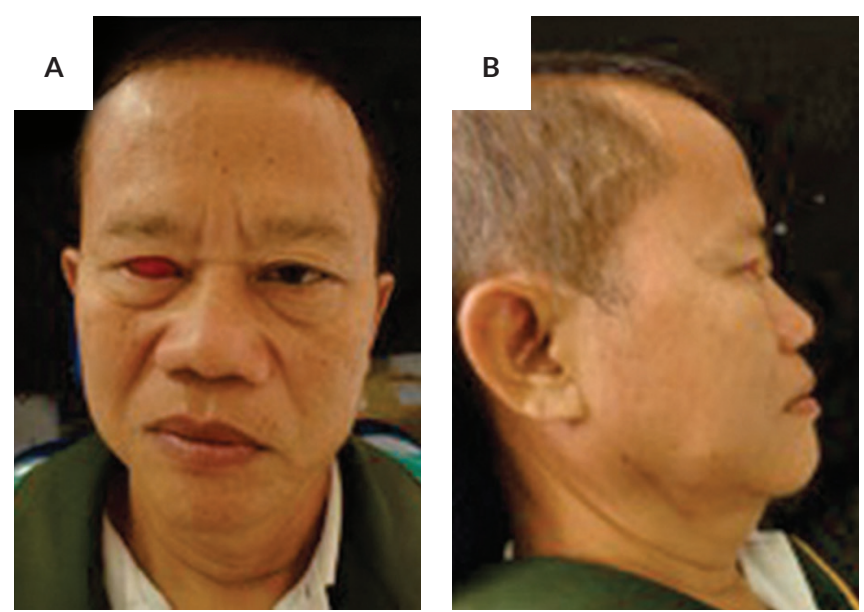

Figure 4. Ocular wax model in socket. (A) Front view; (B) Side view.
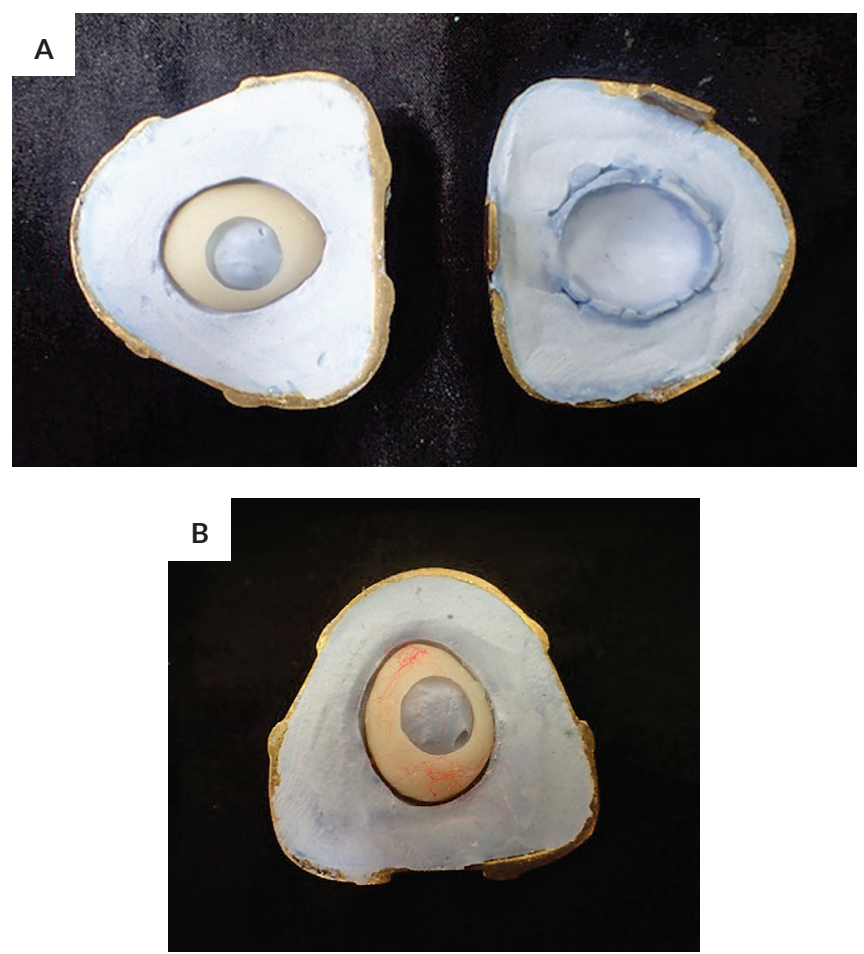

Figure 5. (A) Acrylic ocular packing; (B) Simulated blood vessels using red nylon fiber.

hollow basin and holes for the iris. After the sclera model was smoothened, it was coated with modelling wax and packing on a cuvette. The next procedure was to remove the modelling wax. The iris portion of the prosthesis was obtained from acrylic transparent clear added to acrylic sclera that has been perforated and combined with red nylon fiber to simulate blood vessels in the natural eye (Figure 5).

The prosthesis was polished until smooth and shiny and basic colors of green and red watercolor were mixed to get the same iris color of the patient. Sclera cover was attached
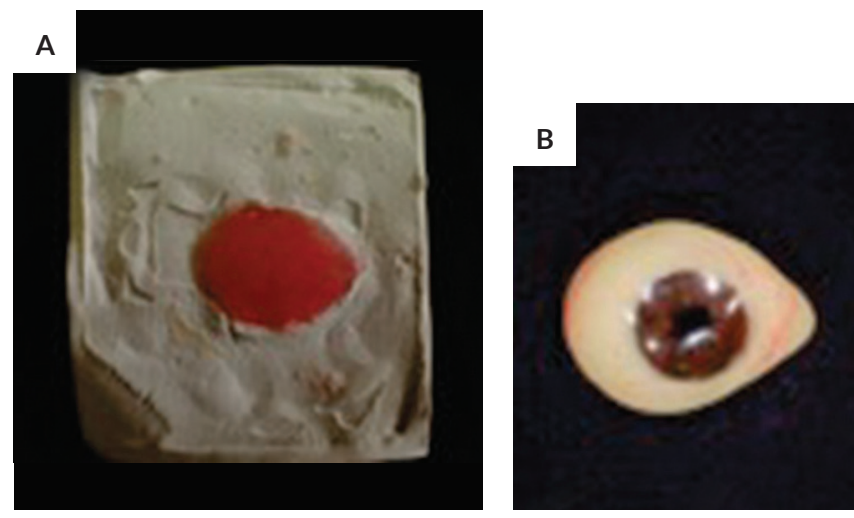

Figure 6. (A) Posterior cover of the hollow ocular prosthesis; (B) Ocular prosthesis.
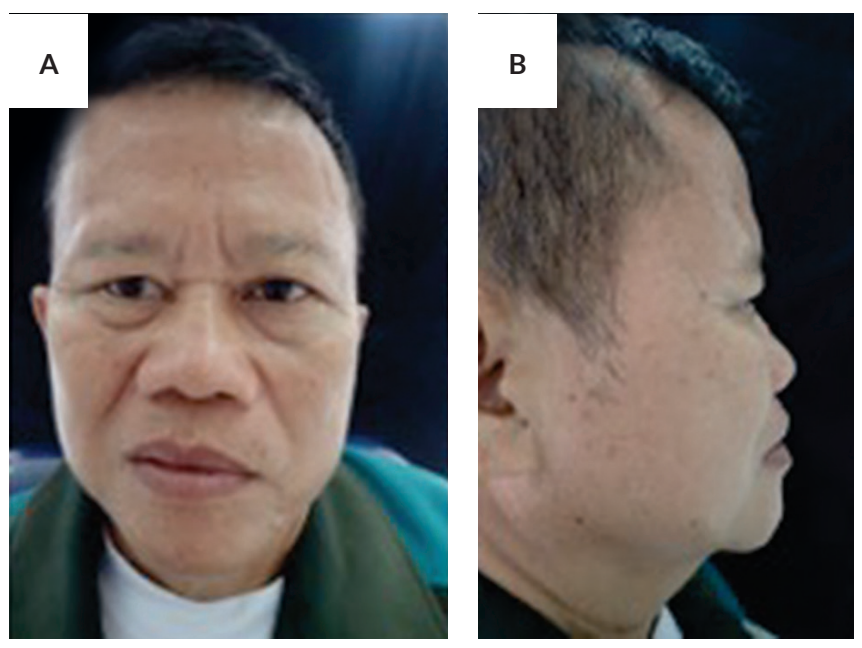

Figure 7. Ocular prosthesis in patient. (A) Front look; (B) Side view.

to the soft tissue of the eye with guide cast to the initial working model. In the final stage of manufacture this ocular prosthesis was mounted close to the sclera on the prosthesis previously made using self-cure acrylic and polished to get good results. During installation, we evaluated the ocular prosthesis as to aesthetics, retention, comfort and ease of doing various eye movements. Post-installation instructions were given for maintenance of prostheses (Figures 6 and 7).

\section{DISCUSSION}

The eye is a vital organ, not only as an organ of vision but also as a component of facial expression. The eyeball is in the orbital cavity that protects the eye from trauma and can move because of the support of the ocular muscles. Losing the eyeballs can cause facial deformities which will result in psychological and emotional problems for the patient. Most patients will experience a significant increase in stress due to adjustment of functional disability and social reactions to changes in the patient's face. ${ }^{6}$ 
The patient lost an eyeball from birth due to a congenital defect, also known as anophtalmia. Anophthalmia is a rare disorder in the development of primary optic vesicles. Anophthalmia has an incidence of $0.18-0.4 / 10,000$ births. Anophthalmia refers to the absence of the eyeball in the presence of the ocular adnexa (eyelid, conjunctiva, and lachrymal apparatus). ${ }^{78}$ One of the reconstruction methods for anophtalmia is the ocular prosthesis. There are two types of ocular prostheses based on their manufacture, stock ocular prosthesis and custom-made prosthesis. A prosthesis that is well adapted to the defect can improve the patient's psychological state, confidence level, and aesthetic value. ${ }^{9}$

Making ocular prostheses has been known to humans since ancient times. Replacement of the lost eye due to surgery or congenital abnormalities must be as soon as possible to help ease the psychological burden for patients and to improve social acceptance. The prosthesis must be placed correctly and restore the normal eye-opening, support the eyelids, restore movement, and must be aesthetically pleasing. ${ }^{5}$ Ocular prosthesis can be specially made according to patient's condition. Stock eye prosthesis often has bad fit, aesthetics, and eye movement. ${ }^{2}$ Custom-made eye prosthesis has the advantage of adaptation close to the network, maximum convenience and restoration of full physiological function to eye and its accessory organs. ${ }^{9}$

The solid ocular prosthetic devices have a considerable weight that has to be borne by the lower eyelid and deep superior sulcus. This can cause laxity of the eyelid in the long term, further impairing retention, aesthetic appearance, and function. The hollow eye prosthesis construction can solve this problem by reducing the overall weight of the prosthesis by as much as $26 \%$. In addition, a light ocular prosthesis enhances patient comfort by allowing long-term wear. ${ }^{10,11}$

There are several techniques used to make a lightweight ocular prosthesis, Aggarwal et al. used spacer wax to hollow out the prosthesis, which was then removed by drilled pinholes in the prosthesis and wax removal procedures. ${ }^{12}$ Kavlekar et al. used the lost-salt technique, which is to put in an appropriate amount of salt to reduce the weight of the prosthesis. ${ }^{10}$ These techniques use a filler that can deform under the pressure of flask closure, resulting in an uneven thickness of the eye prosthesis wall. Thus, the definitive strength of the prosthesis that is desired cannot be ascertained. ${ }^{11}$ In this article, the reduction of the prosthesis weight is carried out by manually grinding the prosthesis body so that the desired thickness of the prosthesis can be predicted.

In the manufacture of custom-made eye prostheses, several studies showed that most of the manufacturing stages were similar; starting from impression making, molding, wax pattern making, adjusting the wax pattern and positioning the iris, flasking and curing, iris colouring, finishing and polishing, and insertion. 5 , The initial consultation and evaluation of a patient prior to fabrication of an ocular prosthesis provides insight into prognosis. The evaluation should include a physical and psychological appraisal of the patient, including the desires and expectations of the patient related to the proposed prosthesis. The importance of a patient's understanding of these aspects relative to the success (or failure) of the prosthesis cannot be overemphasized. ${ }^{13}$

During the procedure, the patient should be seated in an upright position with the head supported by the headrest. This position allows the natural positioning of the palpebral and surrounding tissue relative to the force of gravity. The stock tray should be placed into the defect before making the impression to determine the proper orientation and fit without overextension. ${ }^{13}$

Manually staining the iris requires a lot of skill and time, Chiramana et al. suggest using a digital image of the normal adjacent eye for iris making, so it can provide better aesthetics and save time. ${ }^{3}$ In addition, there are also stock iris disks available in various iris colors. One needs to be careful to choose the right color and size of the iris. ${ }^{14}$

In some cases, anophthalmia has a small orbit with a narrow palpebral fissure and a shrunken fornix. This presents challenges to therapeutic design and placement of conventional prosthetics Thus, sometimes there is a need for surgical enlargement of the palpebral fissure and conjunctival $\mathrm{sac}$ and custom placement of conformers followed by placement of a conventional ocular prosthesis to provide excellent facial function, appearance, and symmetry for the patient. ${ }^{15}$

The retention of the ocular prosthesis is also something that must be considered in addition to aesthetics so that the patient feels comfortable and calm when wearing the prosthesis. There are several retention methods that can be used, for example, anatomical retention, mechanical retention, magnets, adhesives, and implants. ${ }^{16}$ In this case, we used the anatomical retention obtained from the anatomical undercut, which is obtained from the soft tissue structure around the eye and palpebra. In our patient, the soft tissue around the eyes and palpebral muscles were normal so they were adequate for retention of the ocular prosthesis.

A properly fitted and acceptable custom ocular prosthesis has the following characteristics: retains the shape of the defect socket, prevents collapse or loss of shape of the lids, provides proper muscular action of the lids, prevents the accumulation of fluid in the cavity, maintains palpebral opening similar to the natural eye, mimics the coloration and proportions of the natural eye, and has a gaze similar to the natural eye. ${ }^{13}$ The patient felt satisfied with the prosthesis that we made, both from the aesthetic that looks natural and similar to the adjacent eye, as well as the comfort of the prosthesis. The patient felt that the prosthesis fit well with the eyeball cavity with no pain nor blockage when the palpebral was functioning.

For daily use, the prosthesis must be removed regularly to maintain tissue health and hygiene. The prosthesis is cleaned using soap and water at normal temperature. When not in use, the prosthesis is immersed in water at normal temperature. ${ }^{17}$ 


\section{CONCLUSION}

Many factors play a role in the successful treatment of the ocular prosthesis in patients with anopthalmia, such as operator skills, defect conditions related to prognosis, the type of ocular prosthesis selected, and the patient's physical and psychological state. The latter includes the patient's wishes and expectations regarding the proposed prosthesis. The hollow custom-made eye prosthesis has several advantages, such as being lightweight so that the patient is comfortable using it for a long time. Since the prosthesis is adapted to the defect condition, the prosthesis is better adapted to improve retention, comfort, appearance and aesthetic function. Most importantly, ocular prosthesis treatment is able to improve the patient's psychological and emotional status.

\section{Acknowledgment}

The paper would not have been possible without the exceptional support from the member of the Prosthodontics Department Faculty of Dental Medicine Universitas Airlangga, a committee of TIMNAS 2020, Dr. Agus, Dr. Rizko, and also Dr. Ratih who have been supportive of my career goals and who worked actively to provide me with the protected academic time to pursue those goals. I am grateful to those I had the pleasure to work with this and other related projects.

\section{Statement of Authorship}

All authors participated in the data collection and analysis and approved the final version of the manuscript submitted.

\section{Author Disclosure}

All authors declared no conflicts of interest.

\section{Funding Source}

No funding support.

\section{REFERENCES}

1. Driscoll CF, Martin A, Freilich AD, Guckes KL, Knoernschild \& Thomas J, McGarry. Ninth Edition. J. Prosthet. Dent. Vol 117(The Glossary Of Prosthodontic Terms Ninth Edition) 2017; 117(5s):E63.

2. Pun SN, Shakya R, Adhikari G, Parajuli Pk, Singh K, Suwal P. Custom ocular prosthesis for enucleated eye: a case report. Nepal Med Coll J. 2016: (2);46-9

3. Chiramana, S. Anne G, Ravuri K, Boppana PP, Kumar S, Appana KA. A time saving method to fabricate a custom ocular prosthesis. J Orofac Res. 2013; (1):42-5.

4. Sikka N, Mishra G, Bala S, Singh P. Fabrication of custom made ocular prosthesis for congenital defect: a case report. 2017; 1(3):27-9.

5. Jamayet N, Srithavaj T, Alam MK. A complete procedure of ocular prosthesis: a case report. Int Med J. 2013; 20(6):729-30.

6. Babu MS, Gopinadh A, Prakash M, Sampath A, Babu JK, Dutt S. Fabrication of orbital prosthesis - a case report. Orofac Sci. 2011; 3(2):6-8.

7. Ragge NK, Subak-Sharpe ID, Collin JRO. A practical guide to the management of anophthalmia and microphthalmia. Eye. 2007; 21(10):1290-300

8. Searle A, Shetty P, Melov SJ, Alahakoon TI. Prenatal diagnosis and implications of microphthalmia and anophthalmia with a review of current ultrasound guidelines: Two case reports. J Med Case Rep. 2018; 12(1):1-7.

9. Gunaseelaraj R, Karthikeyan S, Kumar MN, Balamurugan T, Jagadeeshwaran AR. Custom-made ocular prosthesis. J Pharm Bioallied Sci. 2012; 4(SUPPL. 2-PART 1):177-80.

10. Kavlekar AA, Aras MA, Chitre V. A light weight ocular prosthesis fabricated by a simplified technique : an eye in a day. Int J Contemp Med Res. 2016; 3(6):1591-3.

11. Maskey B, Mathema SRB, Shrestha K, Bhochhibhoya A. A simplified approach to fabricate a hollow ocular prosthesis. J Prosthodont. 2019; 28(7):849-52.

12. Aggarwal H, Kumar P, Singh RD. A simplified method to fabricate a pneumatic ocular prosthesis for large ocular defects. J Indian Prosthodont Soc. 2014; 14(2):106-9.

13. Taylor TD. Clinical maxillofacial Prosthestics. Illinoiss: Quintessence Publishing; 2000.

14. Gupta L, Aparna IN, Dhanasekar B, Prabhu N, Malla N, Agarwal P. Three-dimensional orientation of Iris in an ocular prosthesis using a customized scale. J Prosthodont. 2014; 23(3):252-5.

15. Reddy PSS, Murugesan, Abraham P, Kumar V. Prosthodontic and surgical management of anophthalmia: a case report. J Indian Prosthodont Soc. 2014; 14(1):120-3.

16. Kulshrestha R, Rathod K, Umale V, Sharma V, Porwal A, Jhawar S. Ocular prosthesis in dentistry - a review. Int J Case Stud Clin Res. 2018; 2(6):55-61.

17. Beumer JI, Marunick MT, Esposito SJ. Maxillofacial Rehabilitation. 3rd ed. Chicago: Quintessence Pub. Co; 2011. 278 hal. 